\title{
OPPORTUNITIES AND DRAWBACKS OF MOBILE FLOOD PROTECTION SYSTEMS
}

\author{
Baerbel Koppe ${ }^{1}$ and Birgitt Brinkmann ${ }^{1}$
}

Permanent flood protection systems like dykes and protection walls offer a high level of protection against flooding and need only little maintenance during flood events. Therefore, most high-risk areas are protected by permanent constructions. Problems arise in densely populated areas where no space for dykes is available and less space consuming flood protection walls would cut off traffic lines and obstruct view axes. In these cases, mobile flood protection measures may be a solution to fit both requirements: protection in case of flooding and open access to the floodplain over the remaining time. Furthermore, mobile protective systems can be used as emergency tool against flooding in unprotected low-lying areas and for heightening of permanent flood protection structures in extreme events.

Planning criteria of mobile flood protection like types of application, early warning and deployment time, required personnel, structural failure mechanisms, financial aspects, and essential information politics are discussed in this paper. As the available constructions differ in material, construction, permanent facilities, available protection height, and safety level, a systematization of mobile flood protection systems as well as opportunities and drawbacks of the described constructions are given.

Keywords: flood protection; flood defense; flood management; early warning time; mobile systems; emergency systems

\section{INTRODUCTION}

Floods are one of the most frequent natural hazards worldwide. According to the NatCatSERVICE database of the reinsurance group Munich Re approximately 38\% of the total number of natural catastrophes since 1980 are a consequence of hydrological events like river floods, flash floods, storm surges as well as resulting landslides (Wirtz, 2010). The second major reason for natural catastrophes are meteorological events with a quotient of about $40 \%$ followed by geophysical and climatic events.

Even if a breakdown into windstorm and water losses is not possible, the flooding caused by the Hurricane Katrina can be assumed as the flooding with the highest economical losses for more than 100 years amounting to US\$ 81 billions at the US coast (Blake et al., 2007 and FEMA, 2010). The second most expensive flooding took place in China in 1998 with more than US\$ 30 billions at the rivers Yangtse and Songhua. In Europe, the flooding at the rivers Elbe and Danube in 2002 caused damages of US\$ 21 billions (Munich Re, 2005).

Such major events cause public attention; nevertheless a fact frequently overlooked is that small local events cause approximately $50 \%$ of total flood damage (Plate, Merz, 2001). To avoid fatalities and damages it is necessary to select the appropriate measure of flood control for a specific site. Even with technical measures it is not possible to eliminate the risk but it is obvious that taking precautions pays off. Every Dollar spent on flood control measures may save many times this amount in damage. Thus, it is important to think about the right prevention strategy and practicable solutions.

Beneath dykes and floodwalls also mobile constructions are a solution for flood protection especially in densely populated areas where no space for permanent structures is available. In addition, permanent structures may obstruct heavily the view onto the water body. In these cases, mobile flood protection measures may be a solution to fit both requirements: protection in case of flooding and open access to the floodplain over the remaining time. Furthermore, mobile protective systems can be used as emergency tool against flooding in unprotected low-lying areas and for heightening of permanent flood protection structures in extreme events.

Mobile flood protection systems differ in material, construction, permanent facilities, and available protection height. In the following, a systematization, description and assessment of different mobile protection systems is given. Initially, planning criteria of mobile flood protection like types of application, early warning and deployment time, required personnel, structural failure mechanisms, financial aspects, and essential information politics are discussed.

\section{PLANNING CRITERIA OF MOBILE FLOOD PROTECTION}

Considering the use of mobile flood protection systems, in particular safety-related aspects have to be accounted for. The mode of operation, construction and the usable materials are dependent on

\footnotetext{
${ }^{1}$ Institute for Sustainable Use of Natural Resources and Infrastructure Development (ISRI), Leuphana University Lueneburg, Scharnhorststrasse 1, 21335 Lueneburg, Germany
} 
available early warning time, static and dynamic loads from water level, waves, ice pressure and flotsam impact as well as physical stresses due to weathering effects and required protection height.

Beside the general stability with regard to static and geotechnical aspects, the risk of failure of mobile protection systems is mainly dependent on the possibility of a safe assembly of the system. Important parameters are available early warning time, number of skilled helpers mobilized in a short time as well as manageability of protective components even under bad weather conditions.

A strict assembly schedule is mandatory based on locally defined threshold values of forecasted water levels defining action steps. The assembly schedule of mobile flood protection must not leave to the discretionary power of the decision maker.

All in all, a low failure risk of mobile flood protection can only be guaranteed, if technical components as well as administrative conditions are suitable designed.

\section{Types of Application}

Mobile flood protection systems can be designed in two ways: with or without permanent provisions. Mobile systems equipped with permanent provisions are attached to a certain protection line, whereas the location for the installation of mobile systems without permanent provisions can be selected freely. Nevertheless, it is also possible to install the latter on a predefined location similar to systems with permanent provisions.

In case of using stationary mobile systems with permanent provisions or mobile systems without permanent provisions but with a predefined location of installation, the alignment of the protection line is known in advance. Therefore, it is possible to gather information about ruling conditions allowing the execution of required precautions with respect to the application area and the deployed system to guarantee a smooth installation and operation of the system. For example, it is possible to ensure that the protection line is not obstructed by buildings and the local topography and soil conditions allow the use of the protection system. Additionally, the planned deployment at a specific location enables the storage of system components close to the protection line and facilitates the provision of transport equipment adequate to the system as well as to the deployment area.

In case of emergency use of mobile systems without permanent provisions at locations not known in advance, no or only few information on local conditions are available like soil conditions with respect to geotechnical load capacity and permeability (buoyant safety, hydraulic base failure, safety against erosion), topography, existing installations (pipe culverts, walls) as well as water bypaths (sewage systems, trenches). Therefore, it is not possible to adapt the system as well as the location to the anticipated operating conditions prior to the flood event. Furthermore, the installation of the system has to be designed at short notice by the relevant officer-in-charge.

\section{Early Warning Time}

The term 'early warning time' describes the available time span between forecast of a flood water level and its occurrence. The duration of the early warning time is dependent on the rapidity of the water level rise and the reliability of the water level forecast in case of extreme weather conditions. The latter depends on the quality of the used hydro-dynamical model, the density of point observations (meteorological and hydrological data) and the quality of the weather forecast. In general, the better the required quality of the water level forecast, the shorter is the early warning time.

Water level forecasts are generally afflicted with uncertainties, which can be reduced but never be eliminated by an improvement of basic data and forecast models. Input data of water level forecasts are measured and forecasted weather data as well as measured water levels at different gauges. Water level forecasts display measuring and transmission faults of weather and water level data. Furthermore, water level forecasts can never be superior to weather forecasts. Especially in smaller catchment areas small differences in the forecasted and effective track of cyclones can have a significant influence on the precipitation amount in the considered area and therefore on the peak discharge and water level. This is also valid for coastal areas where wind surges are strictly dependent on the track of cyclones.

In addition, mathematical models can display natural processes only simplified. This is also valid for hydro-numerical calculations of flow processes in a hydrographic network and especially for precipitation-runoff-models in larger catchment areas.

In river basins, with increasing forecast periods predicted water levels are more and more dependent on precipitation predictions. Deviations in the precipitation forecast, whether with respect to the amount or spatial as well as temporal distribution of rainfall, lead to inaccuracies in the water level forecast. As single errors accumulate, the uncertainty of the forecast and therefore the deviation of the predicted and the effective water level increases with increasing forecast periods, see Figure 1. 
Generally, in the upper reaches of rivers rapid water level rises have to be taken into account, as the subsoil of the upper catchment area is often impermeable (rock), the relief is steep, and spatially limited short-term heavy precipitation patterns result in floods due to the relatively small size of the catchment area. Rapid water level rises are also the rule in smaller water bodies, even if they are located in the lowlands.

In the lower reaches of rivers the precipitation partly infiltrates and evaporates due to permeable subsoil and large catchment areas. Additionally, the flat relief results in slow transport velocities and only long lasting spatially effective steady rains lead to flood water levels. Therefore, the water level rise in the lower reaches of rivers is generally slowly.

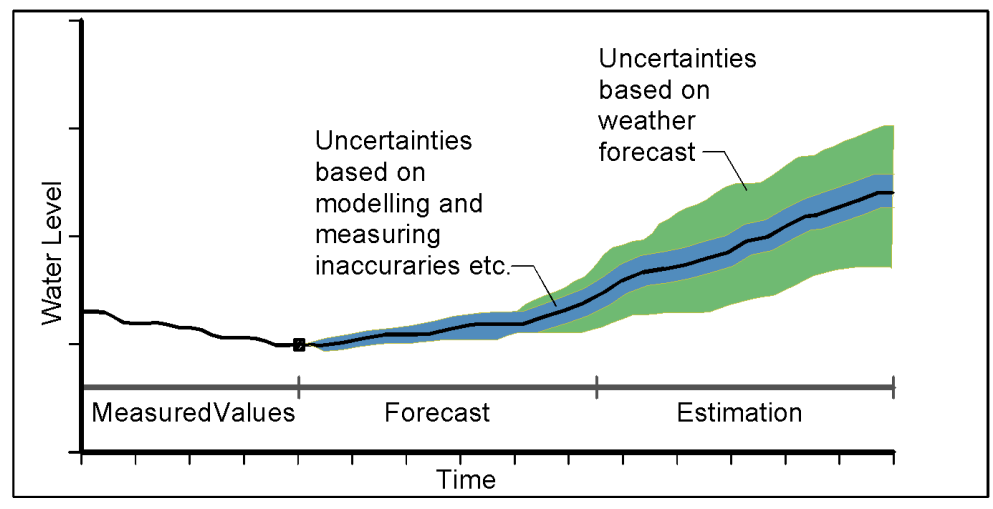

Figure 1. Increasing uncertainties of the water level forecast with increasing forecast period (figure based on BfG, 2009)

These conditions result in very short early warning times in the upper reaches of rivers. In the smaller water bodies the early warning times are often only some minutes, increasing in the main water bodies of the upper reaches to 30 minutes or even to some hours. In the middle reaches of rivers early warning times of several hours up to some days are available, whereas in the lower reaches flood water levels are predictable up to one week or longer in advance.

At coasts, evidence for upcoming wind surges is often predicted one or two days in advance, but the reliability of these forecasts is limited. Normally, coastal water level forecasts with a prediction accuracy of about $0.5 \mathrm{~m}$ are not available more than 12 hours in advance (e.g. Koppe, 2002).

The use of mobile flood protection systems is based on the availability of sufficient time for deployment of personnel, transport of material to the protection line and installation of the protection system.

The available early warning time in smaller water bodies and in upper reaches of rivers is in the range of some minutes to few hours. Hence, the use of mobile systems is normally not possible there. Early warning times of less than 12 hours require generally a large number of at short notice available personnel, short transport ways, and a small numbers of components or a high pre-installation grade of the mobile system.

\section{Deployment Time}

The time period for deployment of mobile flood protection includes:

- Alarm time - time between announcement of an alarm and operational readiness of the personnel

- Loading time - time required for loading of the mobile system components and installation equipment on the means of transport

- Transport time - driving time from the storage location to the protection line

- Safeguard / unloading time - time for safeguarding the traffic lines and for unloading the means of transport at the protection line

- Installation time - time for preparation of the surface at the protection line and for installation of the mobile system including time span to control the correctness of installation

The deployment time varies with type and length of mobile system, lengths and condition of transport ways as well as number and qualification of available personnel.

\section{Financial aspects}

The costs of mobile flood protection are normally higher than these for permanent flood protection measures with comparable safety standard. The following cost types can be distinguished: 
- $\quad$ Planning costs including examination of natural (frequency of flood water levels, loads) and social conditions (damage types and potential, deployment of personnel), objective definition (degree of protection), selection and assessment of appropriate system (analysis of system types), design and layout of selected system

- Purchase costs including - if applicable - purchase and preparation of building ground (leveling, installation of permanent components), purchase of the system considering also weathering effects (lifetime), purchase of installation equipment (tools, means of transport, pumps, etc.)

- Qualification costs including theoretical and practical training of the personnel as well as information of the population

- Allocation costs including storage location and equipment

- Maintenance costs including control and repair of the system

- Deployment costs including personnel, transports, loss of components and equipment

\section{Information of the population}

Using mobile flood protection systems requires comprehensive information of the population especially due to the following circumstances:

- The installation of the protection line must be carried out on the basis of predicted flood water levels. A possible needless installation because of over-predicted water levels is inherent to the system and is no indication for false decision-making.

- Especially in case of emergency use of mobile systems without permanent provisions at locations not known in advance a precautionary evacuation of the endangered area might be necessary.

\section{Personnel}

The required qualification of the personnel is dependent on the type of protection system and the available installation equipment. The training of the personnel includes also the correct behavior in case of overtopping and anticipated system failure.

The number of required personnel is dependent on type and length of the protection system, available equipment, distance between storage and protection line, and duration of available early warning time. Attention should be paid to the fact that the mobile system not only has to be installed but also observed and possibly repaired during the deployment.

After the end of the flooding event the mobile components have to be uninstalled, cleaned, and stored.

\section{Failure types}

Generally, the failure of mobile flood protection systems can be distinguished into five types:

- $\quad$ Sliding (also rolling)

- Tilting

- $\quad$ Failure of stability (due to poor layout, capacity overload, or vandalism)

- Leakage without overall failure

- Geotechnical failure

If the static friction between system and underground is not sufficient due to minor friction coefficient or small normal force (buoying upwards of the system), the system may slide in case of acting lateral loads from water levels, waves, currents, and wind. A special case of sliding is the lateral rolling of cylindrical constructions.

A system is in a stable position as far as its centre of gravity is lying normal above the contact patch. Is the centre of gravity normal above the tilting line, the position is unstable and the system may topple over due to smallest interferences if no additional fastening is existent. The steady position of a body is impacted by the geometry of the body itself as well as lateral forces due to wind (static / dynamic), hydrostatic water loads, and hydrodynamic wave, current, and wind loads.

The inner stability can fail in case of capacity overload and/or incorrect installation. Especially high punctual loads, e.g. due to flotsam impact, can lead to failure. Furthermore, mobile systems can fail due to vandalism, which can be encountered only by safeguarding of the system.

Leakages can occur especially at the underground contact area and lateral connection surfaces resulting from design aspects or incorrect installation. Minor leakages are normally acceptable whereas larger leakages with higher current velocities may soak the underground leading to wash out of soil particles at the contact patch and consequently to stability problems.

Geotechnical failure occurs if the system possesses no stable foundation, unstable slopes exist in the protection line or the safety against hydraulic base failure or erosion is not guaranteed. 


\section{Repair of leakages during deployment}

Mobile flood protection systems should offer the opportunity of repair smaller damages during deployment. For this, additional components or system adapted repair kits containing repair materials and tools must be available. Additionally, a training of the personnel of repair situations is necessary, comprising not only technical knowledge but also safety regards.

\section{Risk zones and inspection rounds}

The use of mobile flood protection must not increase the personal risks. Therefore, the nearer range of the protection line is a prohibited area - risk zone - for passersby. This lowers also the risk of vandalism.

The width of the risk zone can be defined as follows according to the possible protection height (VKF / BWG, 2004a):

- Protection height up to $0.6 \mathrm{~m}: 3$ up to $10 \mathrm{~m}$ risk zone width

- Protection height 0.6 up to $1.2 \mathrm{~m}: 10$ up to $20 \mathrm{~m}$ risk zone width

- Protection height 1.2 up to $2.0 \mathrm{~m}: 20$ up to $50 \mathrm{~m}$ risk zone width

Regular inspection rounds for monitoring the protection line are necessary to ensure an early recognition of leakages, damages, dislocations, and deformations.

\section{System height}

Generally, mobile systems offer only limited protection heights. The highest possible heights can be realized with stationary mobile systems with permanent provisions providing also an anchorage of the system. Depending on the stability capacity of these systems and geotechnical conditions at the predefined protection line, system heights of several meters are feasible. The deployment of such high mobile systems generally requires comprehensive design calculations and the preparation of a detailed installation schedule.

Lower maximum heights are recommended for systems without permanent provisions. These systems used on predefined locations may reach protection heights of up to $1.2 \mathrm{~m}$ and used on nonpredefined locations as an emergency system of up to $0.6 \mathrm{~m}$ (VKF-BWG, 2004a and BWK, 2005). The latter recommended minor protection height is based on the fact that in case of an emergency use of a non-stationary mobile system an examination of subsoil conditions is usually not possible within the available early warning time. Therefore, the risk of hydraulic base failure in case of higher hydraulic gradients is significant.

As flood water level prediction is afflicted with uncertainties, flood water levels may occur lower or higher than predicted. Therefore, also the system behavior in case of overtopping must be considered in the selection of system type and operational planning of mobile flood protection. Unfortunately, many mobile systems show unfavorable behavior like sudden failure in case of overtopping and exceeding load capacities.

\section{Element Weight}

In mobile flood protection large component sizes rationalize the installation works but complicate the transport and handling of components. Dependent on the type of equipment for handling and installation the weight and dimension of the components have to be defined.

In case of non-stationary use of the system, the components must be designed in such way, that four persons at a maximum are able to carry the structure over a distance of at least 30 meters without severe exhaustion. A maximum weight can be defined to $100 \mathrm{~kg}$ per component provided that the structure is equipped with carry handles for four persons.

Larger unit weights are possible if the location of deployment is known and means of transport with lifting devices can be used.

\section{De-Installation and Storage}

For de-installation and cleaning of mobile flood protection systems the double to fourfold time as for installation has to be scheduled.

The kind of storage and the selection of storage location is dependant on the type of system and the available early warning time. If a mobile system is designed for a predefined urban area where only short early warning times are available the distance between storage location and protection line must be short and the components have to be stored within the city centre. In case of longer early warning times the storage may also be chosen in a peripheral location offering the possibility of lower storage costs.

Emergency systems for non-predefined locations have to be stored at a central place of the deployment area equipped with good road links. 
All mobile components and required tools and equipment must be stored at a dry, aired, and accessible place. Prior to storage, corrosion protection of metal components must be ensured by cleaning and possibly refreshment of protective layers. Special attention must be given to contact erosion between e.g. aluminum and steel.

Advantageously is the storage in special transport containers where all components and required tools and equipment as well as spare parts are assembled.

Maintenance works include inspection, test-installation, and repair of the system. For this, systemrelated maintenance schedules have to be compiled. Attention must be paid not only to the stored mobile components but also to permanent components at the protection line.

Test-installations have to be done regularly, usually once a year, for inspection of the components and for training of the installation works.

\section{SYSTEMATIZATION OF MOBILE FLOOD PROTECTION SYSTEMS}

Available mobile flood protection systems differ in material, construction, permanent facilities, and available protection height. In the following, a systematization, description and assessment of different mobile protection systems is given.

Mobile flood protection systems can be divided in stationary and non-stationary mobile systems, see Figure 2. Stationary mobile systems may be partly or completely preinstalled whereas nonstationary mobile systems may be sub-divided in container, mass, flap, and wall systems. In the following, the individual systems are described shortly.

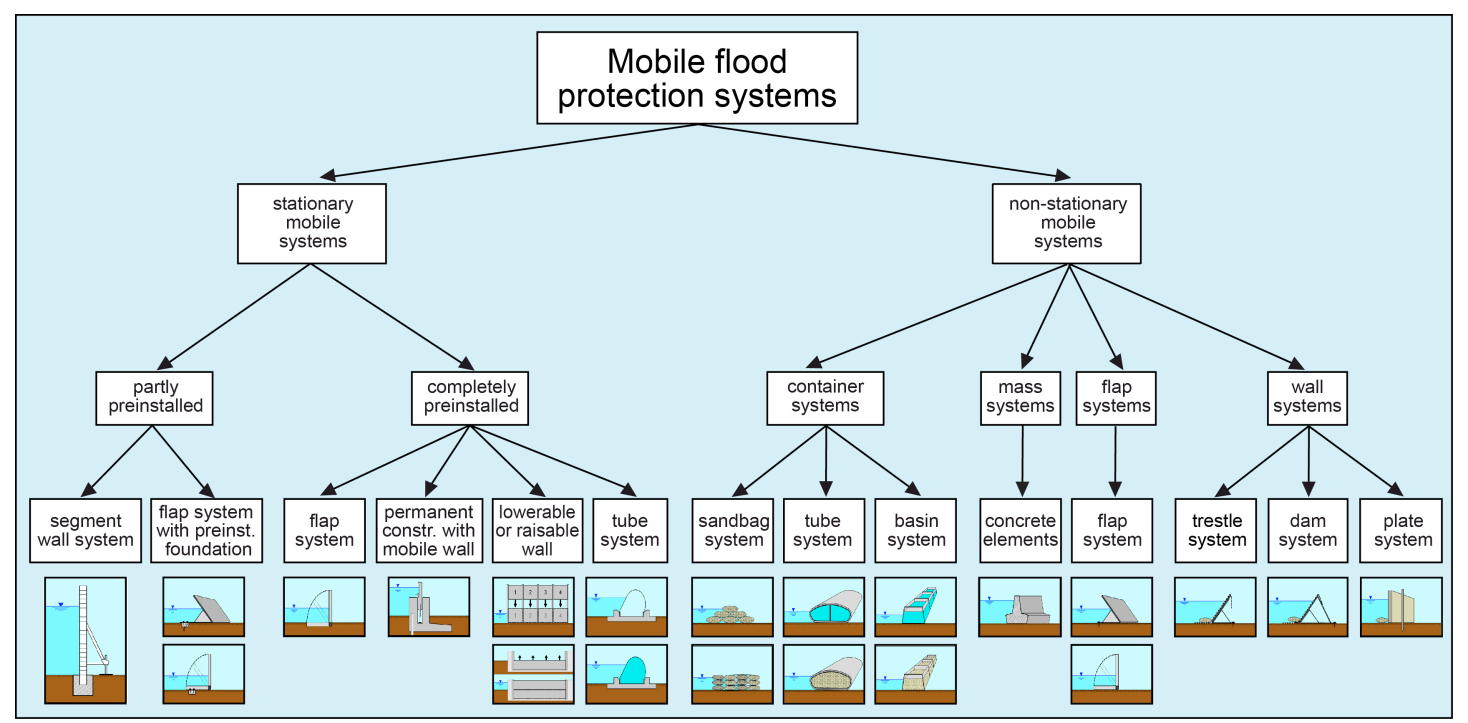

Figure 2. Classification of mobile flood protection systems

\section{Completely preinstalled stationary mobile systems}

Completely preinstalled stationary mobile systems are normally equipped with concrete foundations and mechanical systems to bring the mobile part of the system from the idle in the protection position. The investment costs are generally high for these systems.

\section{Flap system}

Completely preinstalled stationary mobile flap systems consist of a concrete foundation where pivoted flaps are stored at ground level which can be heightened manually or with engine power in case of flooding, Figure 3. Deep foundations offer better support and minimize water bypath. Therefore, the possible protection heights are larger in case of deep compared to shallow foundations. The latter offer advantages if pipelines or cables are crossing the protection line. The single concrete elements of the flap systems are 3 to $10 \mathrm{~m}$ long and up to $2.5 \mathrm{~m}$ high.

\section{$\underline{\text { Partly mobile system }}$}

Partly mobile systems consist of permanent flood protection walls which can be heightened by mobile segments that are stored inside the permanent construction during idle time (Figure 4). The lateral loads have to be transferred completely by the bottom mounting or additional mobile lateral 
supports have to be installed. At any rate, the basic protection line must be strong enough to bear also the additional loads of the mobile section.

The combination of permanent and mobile flood protection elements offers the following advantages:

- Only minor obstruction of the view onto the water area during idle time

- The protection line is fixed and reserved by the permanent basic protection (the alignment cannot be obstructed by parking cars etc.)

- Compared to fully mobile systems the available basic protection allows a later installation of the mobile system and therefore a better assessment of the flooding situation

- Compared to fully mobile systems less personnel is needed for the installation of the partly mobile system

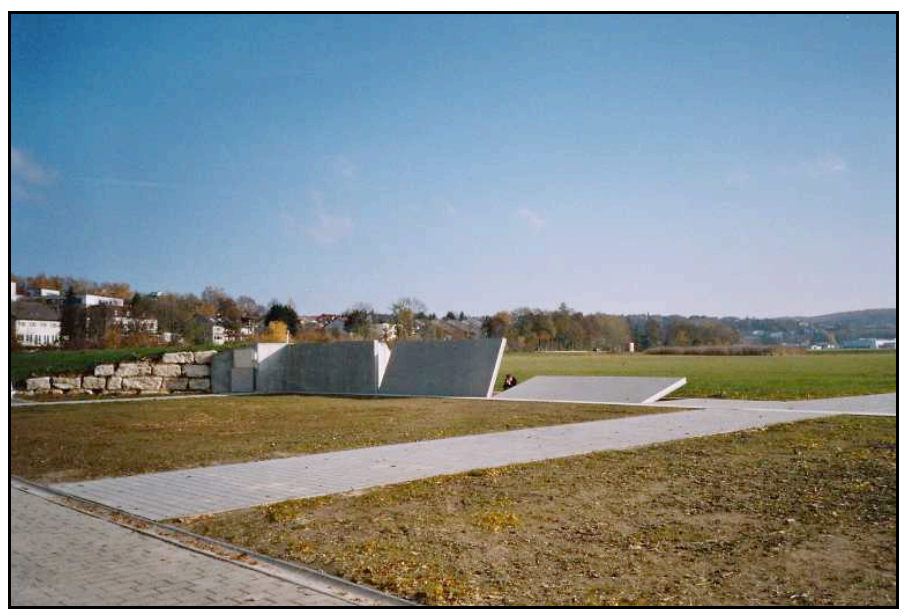

Figure 3. Completely preinstalled stationary flap system in Sinsheim near Heilbronn, Germany (KWS, 2010)

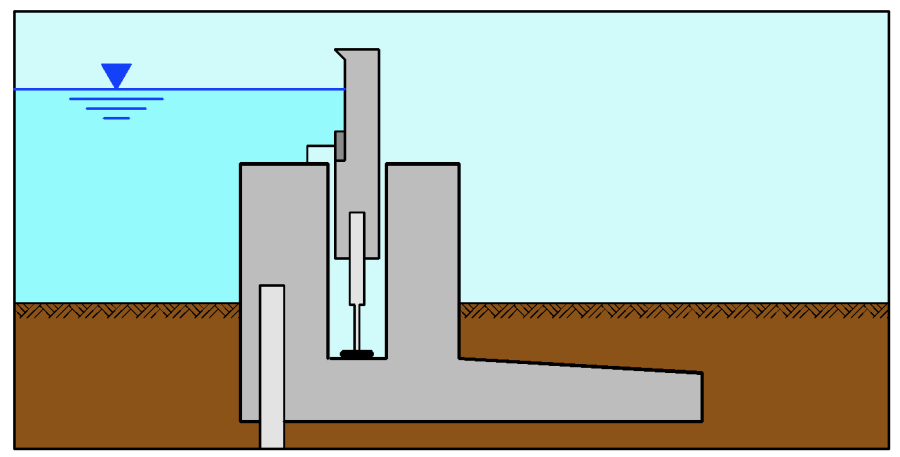

Figure 4. Completely preinstalled stationary partly mobile system - exemplary sketch

Permanently installed lowerable plat system

Permanently installed lowerable plat systems can be used to block road openings or doorways as well as to heighten permanent floodwalls. Depending on the type of application, the segments may be made of metal, glass or concrete. The plat systems are movable installed at the deployment location and can be moved manually or with engine power.

The example in Figure 5 shows a lowerable plat system blocking the doorway of a parking deck. In idle position the plats are stored under the ceiling and are lowered via lateral guiding rails into protection position.

\section{Permanently installed tube system}

Permanently installed tube systems consist of a foundation made of concrete, a hull made of textiles or plastics as well as a filling material, preferably water (Figure 6) or air. For filling of elements 
pumps are in use, whereas a redundancy of filling technique is obligatory. To protect the system in the idle time coverage is required.

These constructions are mainly used as weirs in rivers. Up to now, no longer system lengths are realized in flood protection. Permanent installed tubes offer the opportunity of easy installation but investment costs for foundation, construction and coverage are high.

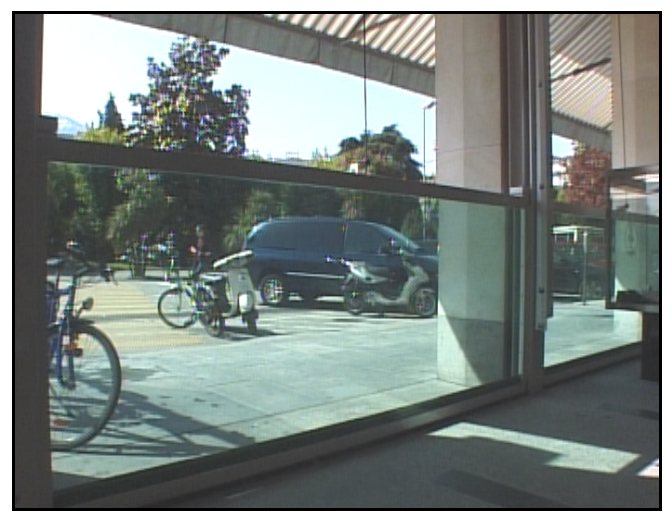

Figure 5. Lowerable glass segment system in protection position in a parking deck in Locarno, Switzerland (KWS, 2010)

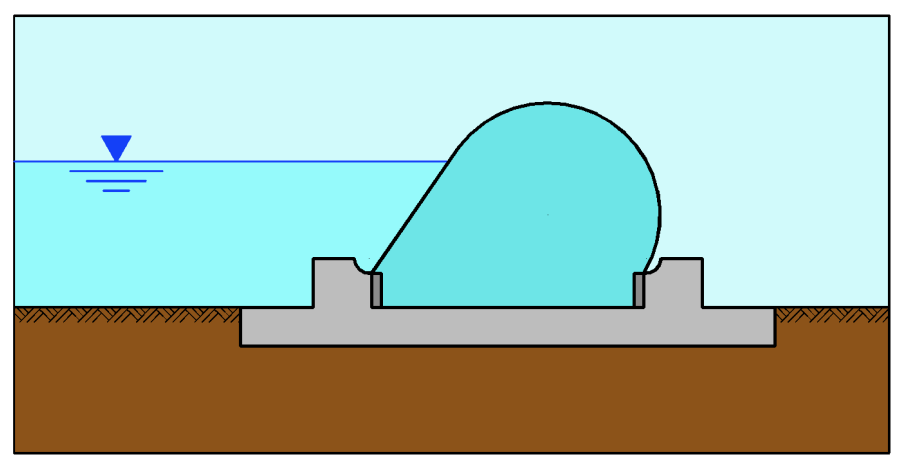

Figure 6. Construction principle of a permanent installed tube system

\section{Partly preinstalled stationary mobile systems}

Partly preinstalled stationary mobile systems are generally equipped with preinstalled load transfer points. The constructions can be divided into segment wall and flap systems.

\section{$\underline{\text { Segment wall system }}$}

Segment walls are the most common system for planned mobile flood protection. They are used as opening closure as well as flood barrier with significant lengths.

Segment wall systems consist of an upright supporting system (often partly permanently installed) between this beams or plates with a length of up to several meters can be positioned (Figure 7). Beam systems with permanent installations can reach protection heights of up to $5.0 \mathrm{~m}$. The supporting system is made of steel, whereas the material of beams or plates can also be aluminium to reduce the weight of mobile parts. In case of material mixture of steel and aluminium contact erosion must be avoided by use of e.g. rubber material.

The foundation of the structure must ensure safety against hydraulic base failure. If the soil itself is not sufficiently stable against scouring not only single foundations underneath the supporting columns but strip foundations along the whole protection line are needed.

\section{Partly mobile flap system}

Partly mobile flap systems consist of reinforced plastic liners or plastic plates fixed at a preinstalled foundation line and connected to each other by zip fasteners or sealing tapes (Figure 8). 
The system can be erected manually with spacer or automatically by the inflow of water. On the market protection heights of 0.5 to $2.0 \mathrm{~m}$ are available.
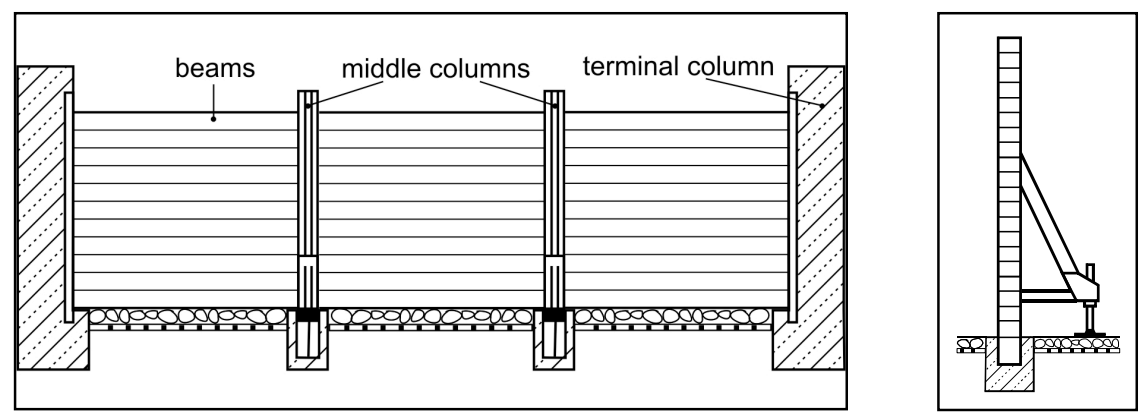

Figure 7. Segment wall system, right: shear force support (Koppe, 2002)

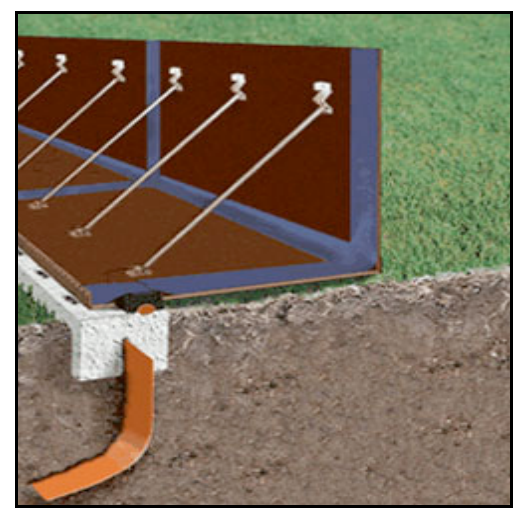

Figure 8. Partly mobile flap system with permanent stripe foundation (AquaFence, 2010)

\section{Completely mobile systems}

Completely mobile systems are mainly used as emergency system without prior planning. They can be divided into container, mass, flap, and wall systems.

Container system made of sandbags

Sandbag systems are in use worldwide. If necessary, sandbag dams can be placed manually without auxiliary technical means. Sandbags offer a high degree of flexibility and the use is very simple but also very demanding in material, work and transport (Figure 9). It is possible to reach protection heights of $1.0 \mathrm{~m}$, with great efforts referring to staff and material resources of up to $2.0 \mathrm{~m}$.

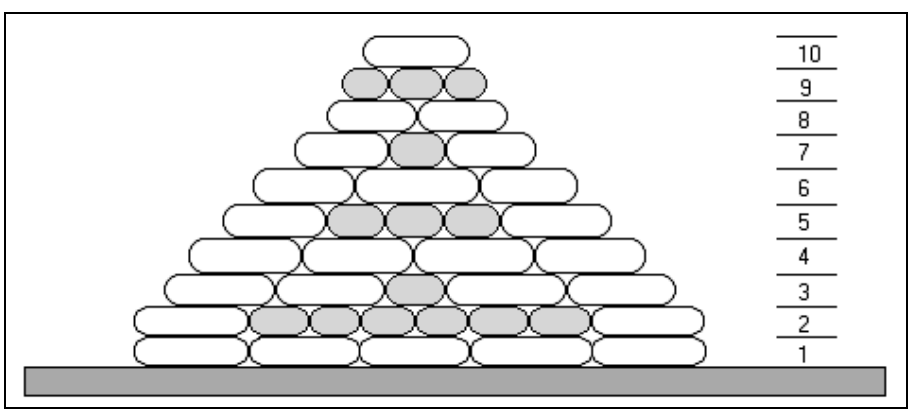

Figure 9. Laying technique of a sandbag dam; cross section, grey parts: transverse laid sandbags (THW, 2010) 
For construction of a $0.5 \mathrm{~m}$ high and $100 \mathrm{~m}$ long sandbag barrier 7,000 sandbags are required (THW, 2001). Only for filling of the sandbags and for installation of the barrier 60 helpers are needed for 1 hour. Additional personnel and time has to be provided for transport of sand and bags to the filling area as well as for transport of the filled sandbags to the deployment area.

\section{Container system made of tubes}

Flexible tubes are made of synthetics like reinforced plastic liner and filled with water or sand. Often an initial filling with air is required for alignment. For filling special equipment is needed like compressors and pumps. No additional anchorage like mounting bars and end constructions are necessary. The fixation of the constructions is done only by their mass effect.

The use of water filled containers saves material and personnel and enables a quick installation. Drawbacks are that the density of the filling material is identically with the density of the source of loading and buoyancy is a problem in case of high stowage heights bearing the potential of sudden failure. Generally, only a stowage height of $70 \%$ of the installation height of water filled constructions is allowed, but due to uncertainties in the water level forecast this threshold might be exceeded in application. Different countermeasures like installation of broad plastic sheets on the waterside of the construction to decrease the hydraulic pressure underneath the system are in use but offer only restricted safety as minor leakages in the plastic sheet may lead to a dysfunction of the safety system. Other countermeasures to avoid sudden failure are currently in development in the research project HWS-MOBILE conducted by Leuphana University Lueneburg together with Hochschule Muenchen, Optimal Planen Menden and Karsten Daedler Trittau with financial assistance of the German Ministry for Economy and Technology. Results will be available in the year 2011.

Difficulties may arise in the fixation of water filled tubes. Especially in case of dynamical loads, e.g. wave loads, cylindrical elements may roll aside and change their position uncontrollably. This can be avoided by e.g. the use of two cylindrical inner tubes and one cylindrical outer tube (Figure 10). Due to the friction between the two inner tubes as well as between the inner and the outer tubes the movement of the construction can be minimized.

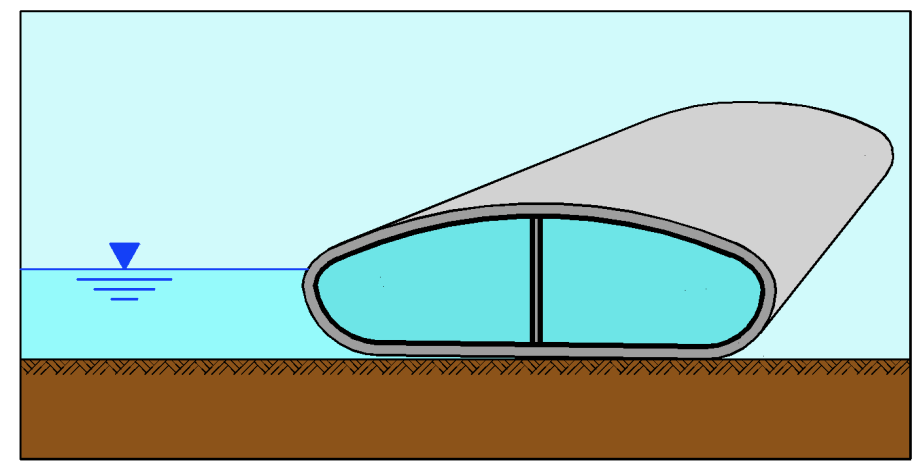

Figure 10. Exemplified non-stationary tube system with two inner and one outer tube

A stable position of the tube system can also be achieved by a special shape forming by means of inner reinforcements (Figure 11) or by linking two cylindrical tubes together (Figure 12). The development and improvement of such systems is in process within the research project HWSMOBILE. The prototypes are fabricated by the partner companies Karsten Daedler and Optimal.

The lengths of the tube elements of different systems vary from 5 to $60 \mathrm{~m}$. For the creation of longer protection lines single tube elements are linked together. The maximum protection height of commercially available constructions filled with water is approx. $2 \mathrm{~m}$. For emergency use such system heights are not recommendable, see section 'System height'.

\section{$\underline{\text { Container system made of basins }}$}

Basin systems consist of a frame construction in which a fitted textile or plastic material is fixed which can be filled with water or solid matters. In case of short early warning times a filling with sand or other solid material is normally not possible due to the required transport times. The filling with water enables a fast installation but bears the disadvantage of a filling with low density, see chapter 'Container system made of tubes'. 


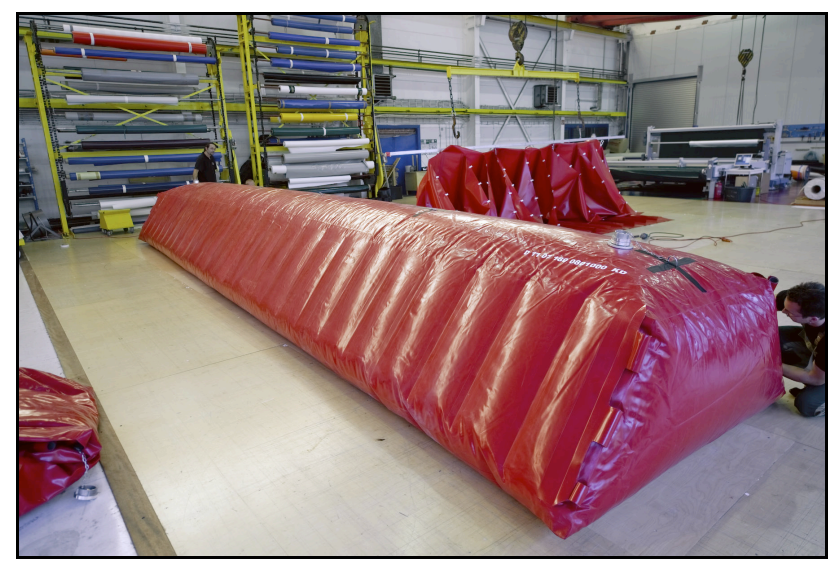

Figure 11. Tube system prototype with inner reinforcements made by the company Karsten Daedler in Trittau, Germany

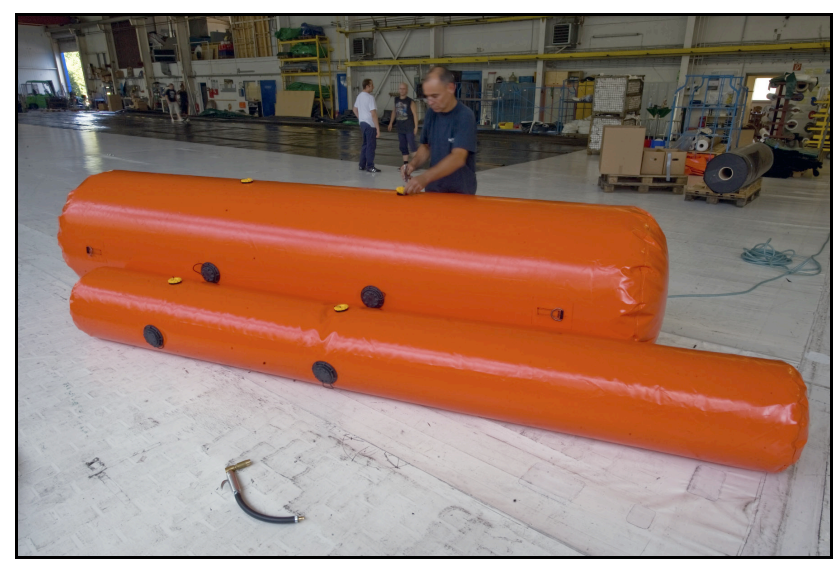

Figure 12. Tube system prototype made of two jointed cylindrical tubes made by the company Optimal in Menden, Germany

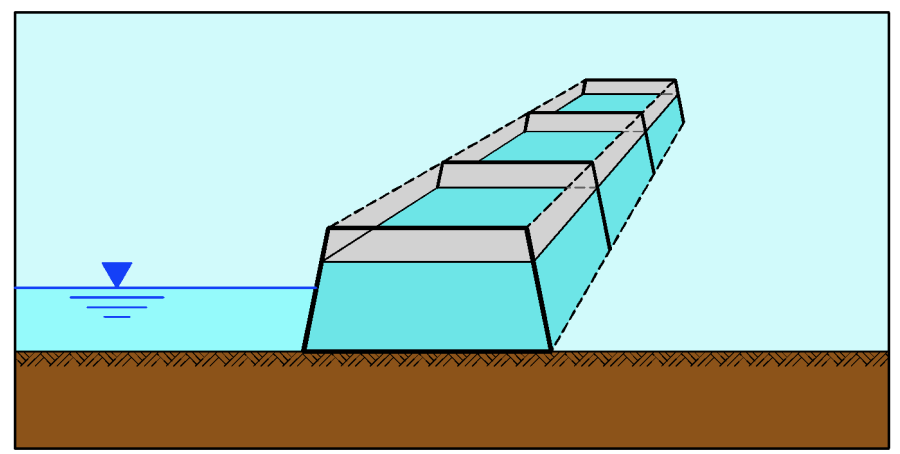

Figure 13. Basin system filled with water

\section{Mass system}

Mass systems are hard to manage and are only in use if high loads require huge dead weights. This is the case in torrents where the construction has to withstand not only high flow velocities but also considerable bed-load discharges. An example for a mass element normally used as slope protection is a cantilever wall element made of concrete, see Figure 14. This kind of element can be used without any further sealing, only by putting them side by side. 


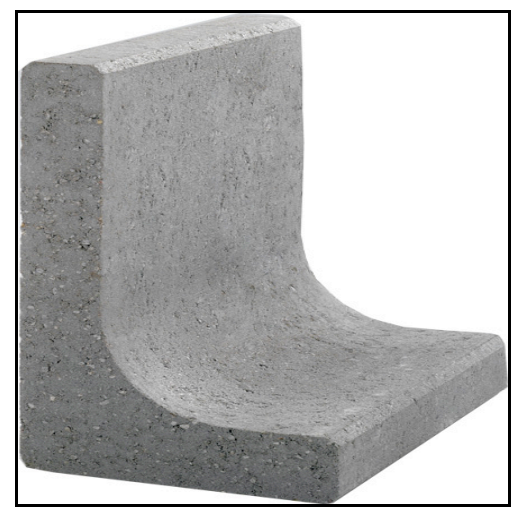

Figure 14. Concrete element usable as mobile mass system (Rekers, 2010)

\section{Flap system}

Mobile flap systems may consist of solid plastic sheets or flexible plastic material (Figure 15). The opening of the flap is directed towards the waterside so that the construction will be filled automatically with water in case the water level rises. Where necessary, a retaining against sliding can be installed in form of pegs or sandbags.

Flap systems are especially suited to dam frontal flow of waters. Up to now, such systems are especially used in Great Britain to protect properties against flash floods with water levels of up to 0.5 to $0.7 \mathrm{~m}$. Between system installation and occurrence of flood water level the system is lying flat on the ground enabling a free access to the protected area. The installation time of such system is quite short with approx. 1 hour for a length of $100 \mathrm{~m}$ in case 2 helpers are available.

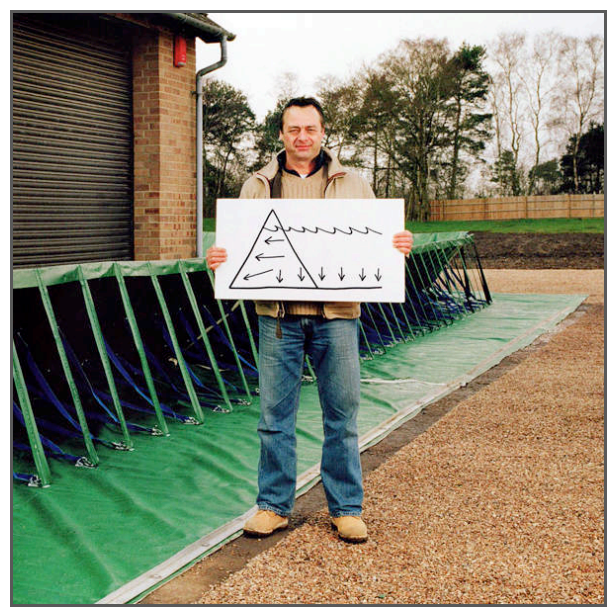

Figure 15. Mobile flap system made of flexible plastic material (Rapidam, 2010)

\section{Trestle system}

Trestle systems consist of four parts: supporting elements, wall units, plastic liner and load elements (Figure 16). The wall units are laid on the supporting elements and are sealed with plastic liner, which is charged by sandbags on the waterside base. Often, ground anchors are used to prevent from sliding.

\section{Dam system}

Mobile dam systems differ from trestles therein that one element acts as both, supporting system and wall (Figure 17). Leak tightness is achieved using plastic liner and sandbags. 


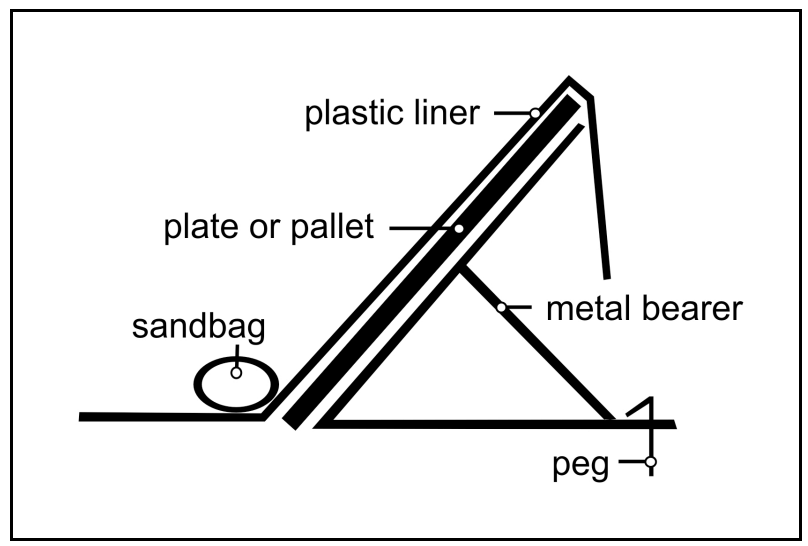

Figure 16. Trestle system

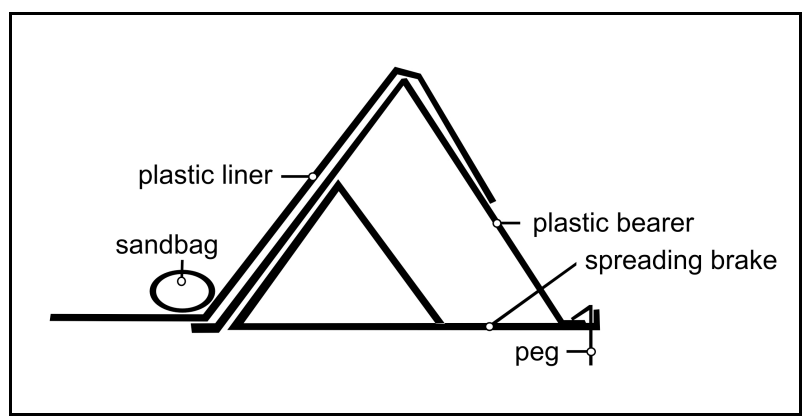

Figure 17. Mobile dam system

\section{Plate system}

Plate systems can be used as emergency systems as their basics can be provided from construction stock grounds. Casings are erected upright mounted by reinforcing steel, which is driven into the ground. With these makeshifts it is possible to reach protection heights of up to $0.5 \mathrm{~m}$.

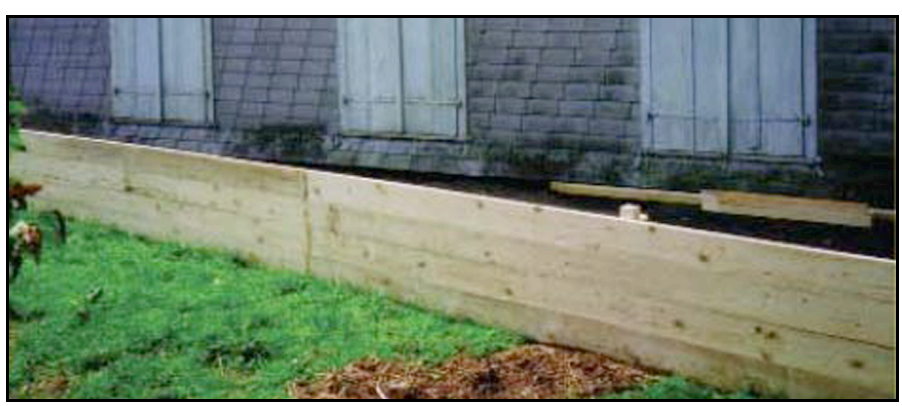

Figure 18. Emergency plate system (VKF / BWG, 2004b)

\section{CONCLUSIONS}

A variety of mobile flood protection systems are on the market fulfilling different security and manageability levels. Therefore, it is necessary to analyze properly the requirements and site conditions in every specific application. Based on such comprehensive investigations, mobile flood protection systems might be the appropriate solution for both, emergency use and planned flood protection.

Generally, the following opportunities and drawbacks of mobile flood protection systems can be stated:

Opportunities of mobile flood protection systems:

- Space saving in densely populated areas

- Urban planning advantages due to open access to the water body 
- Fully mobile protective constructions offer advantages as emergency systems especially in comparison with time and staff consuming sandbag systems

Drawbacks of mobile flood protection systems:

- Mobile protective systems are more expensive than permanent solutions offering the same safety degree

- Constructions without permanent installations offer only low protection heights

- Some systems are highly time / staff consuming in installation and de-installation

- Many mobile structures tend to sudden failure in case of capacity overload

- In emergency use no safety check with respect to geotechnical aspects is possible

\section{ACKNOWLEDGEMENT}

The works in the research project HWS-MOBILE were executed with financial assistance of the German Ministry for Economy and Technology on the basis of a resolution of the German Parliament. The authors kindly acknowledge this financial support.

\section{REFERENCES}

AquaFence, 2010: Information on the Website: http://www.aquafence.com. Status August 2010.

BfG, 2009: "Genauigkeit der Wasserstandsvorhersagen". Information on the Website of the Bundesanstalt für Gewässerkunde (BfG): http://www.bafg.de/M2/DE/01_Referat_M2/04

Vorhersagen/Genauigkeit/genauigkeit_node.html (website accessed September 2010).

Blake, E.S., E.N. Rappaport; C.W. Landsea, and NHC Miami. 2007: The deadliest, costliest, and most intense United States tropical cyclones from 1851 to 2006 (and other frequently requested hurricane facts). NOAA Technical Memorandum NWS TPC-5. National Weather Service, National Hurricane Center, Miami, Florida.

BWK, 2005: "Mobile Hochwasserschutzsysteme - Grundlagen für Planung und Einsatz". Merkblatt 6, Bund der Ingenieure für Wasserwirtschaft, Abfallwirtschaft und Kulturbau (BWK) e.V., Sindelfingen.

FEMA, 2010: The 100 Most Expensive Natural Disasters of the 20TH Century. Information at the Website: http://www.disastercenter.com/disaster/TOP100C.html, Federal Emergency Management Agency, June 2010.

Koppe, B., 2002: "Hochwasserschutzmanagement an der deutschen Ostseekueste" (Flood management at the German Baltic Sea coast - dissertation). Rostocker Berichte aus dem Fachbereich Bauingenieurwesen, Issue 8 University Rostock, 2002.

KWS, 2010: Information on the Website www.kws-stag.ch (website accessed September 2010)

Plate, E.; Merz, B. (ed). 2001. Naturkatastrophen - Ursachen, Auswirkungen und Vorsorge (Natural hazards - causes, consequences and precautions). Schweizerbart'sche Verlagsbuchhandlung, Stuttgart.

Rapidam, 2010: Information on the website: http:/www.floodguards.com/rapidam/ case_studies.html (website accessed September 2010).

Rekers, 2010: Information on the website http://www.rekers-beton.de/ winkelstuetzwaende.php. Status: (website accessed September 2010).

THW, 2001: Handbuch Hochwasserschutz und Deichverteidigung. Bundesanstalt Technisches Hilfswerk, Bonn.

THW, 2010: Deichverteidigung und Hochwasserschutz. Deutsches Technisches Hilfswerk. www.deichverteidigung.de (website accessed September 2010).

VKF / BWG, 2004a: "Entscheidungshilfe Mobiler Hochwasserschutz". Vereinigung kantonaler Feuerversicherungen, Bern; Bundesamt für Wasser und Geologie, Biel.

VKF / BWG, 2004b: "Mobile Flood Protection, Leaflet". Vereinigung kantonaler Feuerversicherungen, Bern; Bundesamt für Wasser und Geologie, Biel.

Wirtz, A. 2010: The year in figures. In: Topics Geo - Natural catastrophes 2009, Analyses, assessments, positions. Munich Re, p. 34. 